\title{
In-Situ Synthesized Myoglobin Imprinted Poly(N-Isopropylacrylamide)/Silica Nanocomposite Gels by Using the Molecular Imprinting Method
}

\author{
Burcu Meşhur ${ }^{1}$, Eylem Turan ${ }^{2}$, Nursel Dilsiz ${ }^{1^{*}}$ \\ ${ }^{1}$ Department of Chemical Engineering, Faculty of Engineering, Gazi University, Ankara, Turkey \\ ${ }^{2}$ Department of Chemistry, Faculty of Art and Science, Gazi University, Ankara, Turkey \\ Email: dilnur@hotmail.com
}

Received November 28, 2013; revised December 27, 2013; accepted January 7, 2014

Copyright (C) 2014 Burcu Meşhur et al. This is an open access article distributed under the Creative Commons Attribution License, which permits unrestricted use, distribution, and reproduction in any medium, provided the original work is properly cited. In accordance of the Creative Commons Attribution License all Copyrights (C) 2014 are reserved for SCIRP and the owner of the intellectual property Burcu Meşhur et al. All Copyright (C) 2014 are guarded by law and by SCIRP as a guardian.

\begin{abstract}
Temperature sensitive imprinted poly(N-isopropylacrylamide) nanocomposite gels were syntheses via in-situ, free radical crosslinking polymerization of corresponding monomer in nano-sized silica and five different concentrations of myoglobin solution by using the molecular imprinting method. Mb adsorption from five different concentrations of $\mathrm{Mb}$ solutions was investigated by two types of nanocomposite gel systems prepared by non-imprinted and imprinted methods. Nanocomposite gels imprinted with Mb showed higher adsorption capacity and specificity for Mb than nanocomposite gels prepared by the usual procedure. The highest Mb adsorption was observed via the imprinted nanocomposite gels with $12.5 \% \mathrm{Mb}$. In addition, selectivity studies were also performed by using two reference molecules as fibrinogen and hemoglobin. The imprinted nanocomposite gels had higher adsorption capacity for $\mathrm{Mb}$ than the non-imprinted gels and also exhibited good selectivity for Mb and high adsorption rate depending on the number of $\mathrm{Mb}$ sized cavities.
\end{abstract}

\section{KEYWORDS}

Nanocomposite Gels; Poly(N-Isopropylacrylamide); Temperature Sensitive; Myglobin; Free Radical Crosslinking Polymerization; Adsorption; Imprinted

\section{Introduction}

Molecular imprinting is an attractive approach for the generation of recognition sites in macromolecular systems in which a template molecule is used in a casting procedure. Valuable results have been obtained with "bulk" polymers in applications in which strong binding to the template is required, but the development of polymeric matrices with specific catalytic activity has proved to be a bigger challenge. A variety of chemical reactions have been shown to be catalyzed by imprinted polymers [1], but the rate accelerations and turnovers have been, with few exceptions, [2] disappointing [3]. In contrast to bulk monoliths, MIP nanoparticles have higher surface area-to-volume ratios; thus, imprinted cavities are more

\footnotetext{
${ }^{*}$ Corresponding author.
}

easily accessible by the templates and the binding kinetics is improved [4].

Molecularly imprinted nanocomposite gels have already been used as enzyme substitutes in drug delivery systems and antibody substitutes as well as in capillary electrophoresis and in sensors [5-8].

A typical molecular imprinting system usually contains a template molecule, a functional monomer, a crosslinker and suitable solvent, where the functional monomer interacts with the template via non-covalent interactions (hydrogen bonds, ionic and hydrophobic interactions) to form complex prior to the crosslinking reaction [9]. After polymerization the template molecule removed, the complementary cavities with respect to shape and functional groups remained [5].

Temperature sensitive imprinted poly(N-isopropylacrylamide) nanocomposite gels were synthesized via in- 
situ, free radical crosslinking polymerization of corresponding monomer in nano-sized silica. The nanocomposite gels obtained were characterized by FT-IR spectroscopy and transmission electron microscopy (TEM) measurements. The adsorption capacity, adsorption kinetics, initial concentration effects were also discussed. In addition, selectivity studies were also performed by using two reference molecules as fibrinogen and hemoglobin. The imprinted nanocomposite gels had higher adsorption capacity for $\mathrm{Mb}$ than the non-imprinted gels and also exhibited good selectivity for $\mathrm{Mb}$ and high adsorption rate depending on the number of $\mathrm{Mb}$ sized cavities.

\section{Experimental Part}

\subsection{Materials}

NIPA (Aldrich Chemical, Milwaukee, WI, USA) was recrystallized in benzene/hexane. AMPS (Aldrich Chemical), N,N-methylenebis (acrylamide) (MBAAm, Aldrich Chemical), ammonium persulfate (APS, Aldrich Chemical), and N,N,NO ,N0-tetramethylethylenediamine (TEMED, Aldrich Chemical) were used as received. Mb (from horse heart, MW17 kDa) and hemoglobin ( $\mathrm{Hb}$, from rabbit, MW65 kDa) were purchased from Sigma Company (St Louis, MO, USA). Mb (from horse heart, MW17 kDa), hemoglobin (Hb, from rabbit, MW65 kDa) and Fibrinojen (Fbg, MW $340 \mathrm{kDa}$ ) were purchased from Sigma Company (St Louis, MO, USA).

\subsection{Preparation of Nanocomposite Gel}

The purified NIPAM and nanosized silica were dissolved in deionized water. MBAAm (crosslinker), APS (initiator), TEMED (accelerator), and different \% Mb (2.5, 5, $7.5,10,12.5)$ were then added to the solution. Polymerization was conducted for $24 \mathrm{~h}$ at room temperature. The non-imprinted nanocomposite gels were prepared simultaneously under the same conditions without Mb. After polymerization, the resulting nanocomposite gels were purified by immersing in deionized water for three days to remove $\mathrm{Mb}$ and unreacted chemicals. The water was replaced 3 - 4 times every day. The removal of Mb was confirmed by UV spectroscopy at $409 \mathrm{~nm}$. When no typical absorbent band at $409 \mathrm{~nm}$ was observed, it indicated that the $\mathrm{Mb}$ was totally removed or the amount of residual $\mathrm{Mb}$ was too low to be detected after the purification.

\subsection{Adsorption Experiments}

Adsorption kinetics experiments were carried out for the imprinted and non-imprinted nanocomposite gels prepared at various \% Mb solution. Nanocomposite gels were placed in a known concentration of Mb solution at $22^{\circ} \mathrm{C}$ for 3 days. The concentration of $\mathrm{Mb}$ in the solution was determined using a spectrophotometer at $409 \mathrm{~nm}$.
For selectivity experiments, Fbg, $\mathrm{Hb}$, and $\mathrm{Mb}$ were used as reference substrate and their absorption measurements were done at 585, 772 and $409 \mathrm{~nm}$, respectively.

\section{Results and Discussion}

\subsection{FT-IR Spectra of Nanocomposite Gels}

The FT-IR spectra of nanosized silica particles and Mb imprinted NIPAM nanocomposite gel are displayed in Figures 1(a) and (b). In Figure 1(a), the $\mathrm{SiO}_{2}$ band are observed at 1057, 948 and $795 \mathrm{~cm}^{-1}$. The band at 1200 $\mathrm{cm}^{-1}$ in the spectra of the silica nanoparticles is attributed to the Si-O-Si stretching. The band at $1462 \mathrm{~cm}^{-1}$ in the spectra is $\mathrm{Si}-\mathrm{CH}_{2}$ vibration. The broad peak between $3000-3500 \mathrm{~cm}^{-1}$ is attributed to $\mathrm{Si}-\mathrm{OH}$ and $\mathrm{H}-\mathrm{OH}$ groups. A typical amide band $\left(1670 \mathrm{~cm}^{-1}\right)$ which consists of the $\mathrm{C}=\mathrm{O}$ stretch of NIPAM is seen in Figure 1(b).

\subsection{Surface Morphology of the Nanocomposite Gels}

Figure 2 shows the surface morphology and the size of the Mb imprinted PNIPAM nanocomposite gel. The AMPS nanocomposite gels exhibits homogeneous size distribution and average gel size $50 \mathrm{~nm}$. Their geometry and size of the nanocomposite gels are quite regular.

\subsection{Adsorption Kinetics of Mb Imprinted PNIPAM Nanocomposite Gels}

Adsorption kinetics experiments were carried out for the imprinted and non-imprinted nanocomposite gels prepared at various \% $\mathrm{Mb}$ solution. The $\mathrm{Mb}$ adsorption curves are shown in Figure 3. It can be seen that the nanocomposite gels have a rapid increase in adsorption over $8 \mathrm{~h}$, and then it increased slowly with prolonged time. After $10 \mathrm{~h}$, the adsorption process reach the equili-

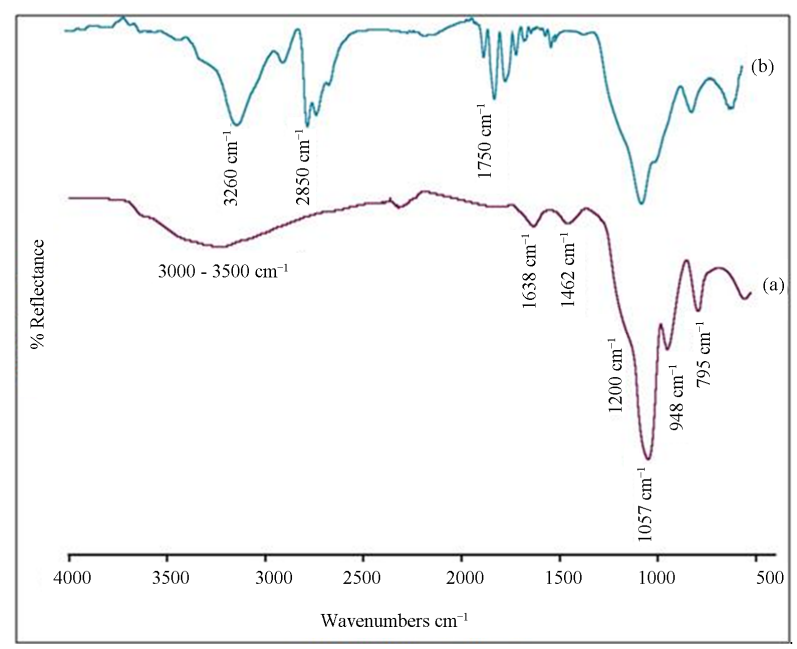

Figure 1. FT-IR Spectra of a) nanosized silica particles and b) Mb imprinted NIPAM nanocomposite gel. 


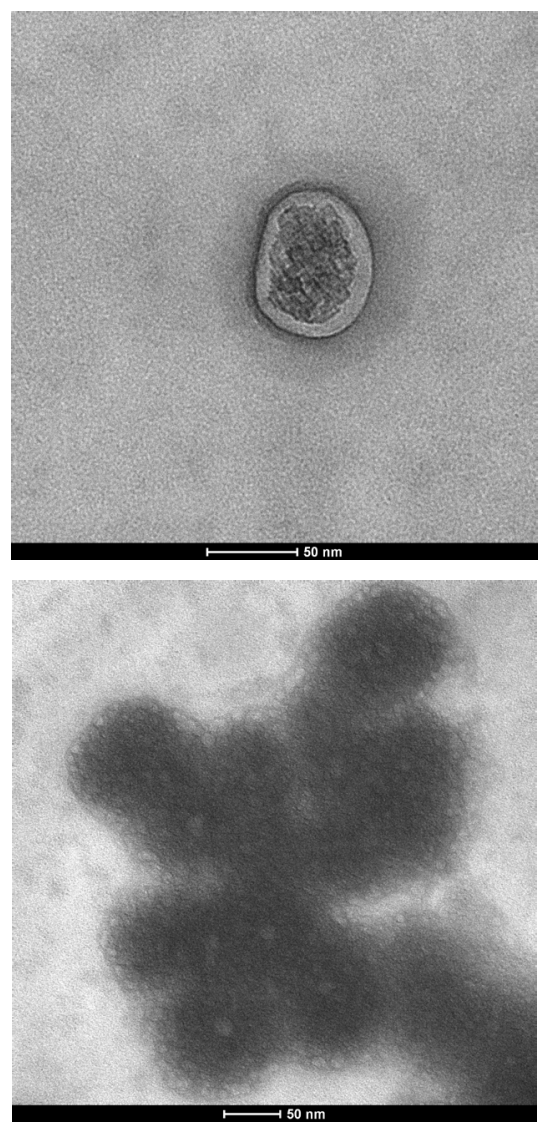

Figure 2. Surface Morphology of Mb imprinted PNIPAM nanocomposite gels.

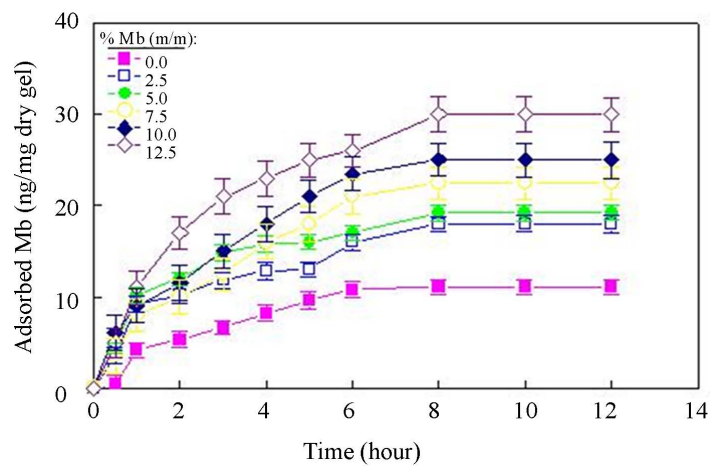

Figure 3. Adsorption Kinetics of Mb imprinted PNIPAM Nanocomposite gels.

brium. In this case, the first part of the kinetic plot shows the $\mathrm{Mb}$ molecules first adsorbed on the surface of the nanogels. The second part of the plot with a smaller slope indicates a slow adsorption rate. This has been observed for both the non-imprinted and imprinted nanocomposite gel. As the adsorption rate does not remain constant, a certain type of rate must be selected for quantitative investigation of the experimental results. Instead of arbitrarily taking the rate measured at a certain adsorption, we have preferred to determine the initial slope of the ad- sorption curves. This enabled us to determine the actual initial adsorption rates directly.

This adsorption equilibrium is most probably a result of the geometric shape affinity between $\mathrm{Mb}$ molecules and $\mathrm{Mb}$ cavities in the nanocomposite gels. Molecular imprinting generates binding cavities that are complementary to the original template in both shape and functionality.

\subsection{Adsorption Isotherm of PNIPAM}

Figure 4 shows the dependence of the adsorbed amount of $\mathrm{Mb}$ on the initial $\mathrm{Mb}$ concentration. As seen this figure, the adsorption values increased with increasing concentration of $\mathrm{Mb}$ and a saturation value is achieved at $\mathrm{Mb}$ concentration of $1.5 \mathrm{ng} \cdot \mathrm{mL}^{-1}$, which represents saturation of the active binding and recognition sites of the nanocomposite gels. The adsorption capacity of the imprinted nanocomposite gels was found to be strongly dependent the initial $\mathrm{Mb}$ concentration.

The adsorption behaviors of the nanocomposite gels were evaluated by the Langmuir isotherm, the experimental data are fitted to the Langmuir equation. The calculated results are listed in Table 1.

As shown in Table 1, the non-linear Langmuir fits well for the $\mathrm{Mb}$ adsorption on the imprinted and nonimprinted nanocomposite gels prepared at different $\mathrm{Mb}$ concentration (correlation coefficient, $\mathrm{rL}>0.943$ ). The maximum adsorption and the Langmuir adsorption equilibrium constant of the imprinted hydrogels were higher than those of the non-imprinted hydrogels according to the adsorption isotherms. The rL values show that favorable adsorption of $\mathrm{Mb}$ on both the imprinted and nonimprinted hydrogels takes place; therefore, the imprinted nanocomposite gels are favorable adsorbers.

The other well known isotherm is the Freundlich adsorption isotherm which is a special case for heterogeneous surface energy in which the energy term in the Langmuir equation varies as a function of surface cover-

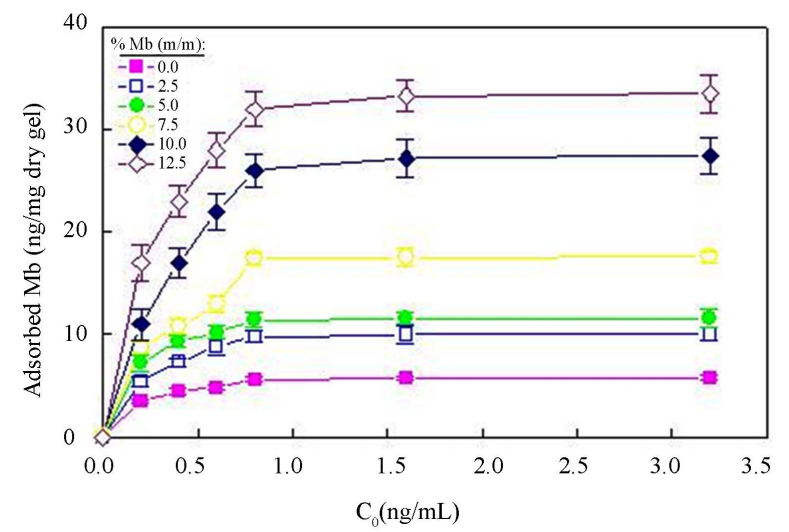

Figure 4. The adsorption isotherms of $\mathrm{Mb}$ on nonimprinted and imprinted nanocomposite gels. 
Table 1. Langmuir isotherm constants of the nanocomposite gels.

\begin{tabular}{cccc}
\hline$\% \mathrm{Mb}(\mathrm{m} / \mathrm{m})$ & $\mathrm{Km}(\mathrm{ng} / \mathrm{mg})$ & $\mathrm{qm}(\mathrm{mL} / \mathrm{ng})$ & $\mathrm{rL}$ \\
\hline 0 & 5.41 & 21.56 & 0.943 \\
2.5 & 13.03 & 18.73 & 0.994 \\
5 & 18.46 & 14.84 & 0.973 \\
7.5 & 27.04 & 10.75 & 0.993 \\
10 & 31.72 & 9.61 & 0.987 \\
12.5 & 38.4 & 4.79 & 0.959 \\
\hline
\end{tabular}

age strictly because of variation of the sorption. The isotherms obtained are well fit by the Freundlich isotherm. The slope of the straight line fit yields $\mathrm{n}$, which is a measure of the heterogeneity of a system. A more homogeneous system has an $\mathrm{n}$ value that approaches unity and a more heterogeneous system has an $\mathrm{n}$ value that approaches zero. The Freundlich isotherm is useful to produce a direct measurement of the adsorption properties. The calculated results from the Freundlich isotherm are also listed in Table 2.

The magnitude of the exponent $1 / n$ gives an indication of the favorability of the adsorption [10]. The values, $n>$ 1 represents a favorable adsorption condition for $\mathrm{Mb}$ adsorption on the hydrogels, and the high correlation coefficients $(\mathrm{rF}>0.915)$ showed that the Freundlich isotherm also agrees well with experimental data. However, $\mathrm{rL}>\mathrm{rF}$ and, therefore, the non-linear Langmuir isotherm fits the experimental data better than the Freundlich one. A good fit of this isotherm reflects monolayer adsorption.

\subsection{Selectivity of Nanocomposite Gels}

The special selectivity tests of non-imprinted and imprinted hydrogels prepared with different temperatures were carried out using $\mathrm{Mb}$ as substrate. The amount of $\mathrm{Mb}$ adsorbed to the imprinted and non-imprinted nanocomposite gels were determined with the equilibrium adsorption method (Figure 5).

The selectivity, $\alpha_{1} \mathrm{Mb} / \mathrm{Hb}, \alpha_{2} \mathrm{Mb} / \mathrm{Fbg}$ and separation, $\beta$ imprinted/ non-imprinted, factors were calculated and are given in Table 3 . The data in Table 3 show that the imprinted hydrogels exhibit high selectivity for the imprinting $\mathrm{Mb}$ molecule compared to $\mathrm{Hb}$ and Fbg. However, the non-imprinted hydrogels exhibit low a values under the same conditions. Although $\mathrm{Mb}$ and $\mathrm{Hb}$ have almost the same isoelectric point $(6.9-7.3), \mathrm{Hb}$ has a larger molecular mass ( $\mathrm{MW} 65 \mathrm{kDa}$ ) than the template $\mathrm{Mb}$ (MW $17 \mathrm{kDa}$ ). Moreover, $\mathrm{Hb}$ is tetrameric protein composed of pairs of two different polypeptides and has a biconcave shape; $\mathrm{Mb}$ consists of one polypeptide and has an ellipsoidal shape [11]. Since the cavities formed by

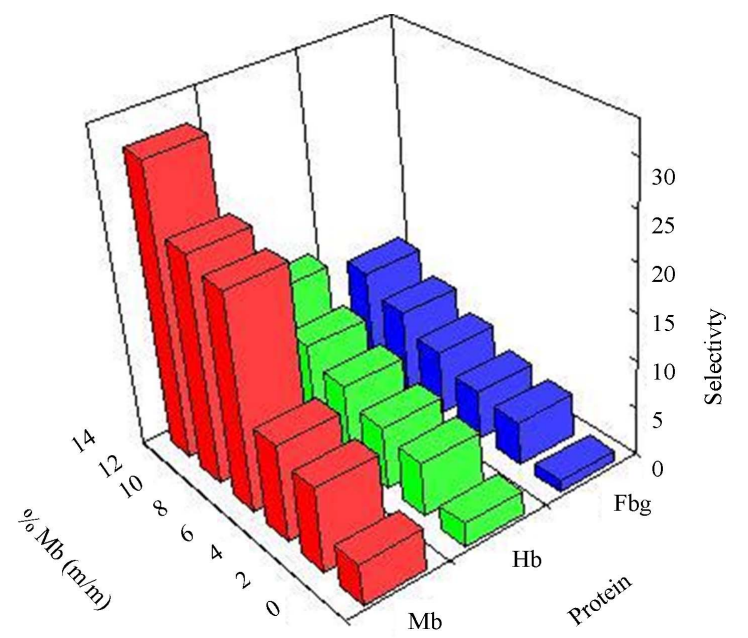

Figure 5. Adsorption capacities of $\mathbf{M b}, \mathrm{Hb}$ and Fbg.

Table 2. Freundlich isotherm constants of the nanocomposite gels.

\begin{tabular}{cccc}
\hline$\% \mathrm{Mb}(\mathrm{m} / \mathrm{m})$ & $\mathrm{Kf}(\mathrm{ng} / \mathrm{g})$ & $\mathrm{n}(\mathrm{mL} / \mathrm{ng})$ & $\mathrm{rF}$ \\
\hline 0 & 6.15 & 4.8 & 0.945 \\
2.5 & 11.18 & 3.7 & 0.953 \\
5 & 17.59 & 4.6 & 0.92 \\
7.5 & 25.33 & 2.1 & 0.915 \\
10 & 32.87 & 3.2 & 0.937 \\
12.5 & 37.28 & 2.7 & 0.909 \\
\hline
\end{tabular}

Table 3. Selectivity $(\alpha 1, \alpha 2)$ and seperation $(\beta)$ factors of the nanocomposite gels.

\begin{tabular}{cccc}
\hline$\% \mathrm{Mb}(\mathrm{m} / \mathrm{m})$ & $\alpha 1(\mathrm{Mb} / \mathrm{Hb})$ & $\alpha 2(\mathrm{Mb} / \mathrm{Fbg})$ & $\beta$ (imp/nonimp) \\
\hline 0 & 1.76 & 3.56 & - \\
2.5 & 1.54 & 1.93 & 2.06 \\
5 & 1.55 & 1.98 & 2.37 \\
7.5 & 2.8 & 3.37 & 5.36 \\
10 & 2.45 & 2.79 & 5.65 \\
12.5 & 2.33 & 2.89 & 7.26 \\
\hline
\end{tabular}

the imprinted hydrogels are matched to the size of $\mathrm{Mb}$, it is very difficult for molecules with a different dimension or molecular mass to enter the cavities

\section{Conclusion}

Temperature sensitive imprinted poly(N-isopropylacrylamide) nanocomposite gels were syntheses via in-situ, free radical crosslinking polymerization of corresponding monomer in nano-sized silica and five different concentrations of myoglobin solution by using the molecular 
imprinting method. Nanocomposite gels imprinted with Mb showed a higher adsorption capacity for Mb than nanocomposite gels prepared by the usual procedure. The highest $\mathrm{Mb}$ adsorption was observed via the imprinted nanocomposite gels with $12.5 \% \mathrm{Mb}$. In addition, selectivity studies were also performed by using two reference molecules as fibrinogen and hemoglobin. The imprinted nanocomposite gels exhibited good selectivity for $\mathrm{Mb}$ and high adsorption rate depending on the number of $\mathrm{Mb}$ sized cavities.

\section{REFERENCES}

[1] C. Alexander, H. S. Andersson, L. I. Andersson, R. J. Ansell, N. Kirsch, I. A. Nicholls, J. O’Mahony and M. J. Whitcombe, "Molecular Imprinting Science and Technology: A Survey of the Literature for the Years up to and Including 2003,” Journal of Molecular Recognition, Vol. 19, No. 2, 2006, pp. 106-180. http://dx.doi.org/10.1002/jmr.760

[2] J. Q. Liu and G. Wulff, "Molecularly İmprinted Polymers with Strong Carboxypeptidase A-Like Activity: Combination of an Amidinium Function with a Zinc-İon Binding Site in Transition-State İmprinted Cavities," Angewandte Chemie International Edition, Vol. 43, No. 10, 2004, pp. 1287-1290. http://dx.doi.org/10.1002/anie.200352770

[3] D. Carboni, K. Flavin, A. Servant, V. Gouverneur and M. Resmini, "The First Example of Molecularly Imprinted Nanogels with Aldolase Type I Activity," Chemistry-A European Journal, Vol. 14, No. 23, 2008, pp. 7059-7065.

[4] S. Shiho, H. Shiigi and T. Nagaoka, "Review: Micro- and Nanosized Molecularly İmprinted Polymers for HighThroughput Analytical Applications," Analytica Chimica Acta, Vol. 641, No. 1-2, 2009, pp. 7-13. http://dx.doi.org/10.1016/j.aca.2009.03.035
[5] A. Poma, A. P. F. Turner and S. A. Piletsky, "Advances in the Manufacture of MIP Nanoparticles," Trends in Biotechnology, Vol. 28, No. 12, 2010, pp. 629-637. http://dx.doi.org/10.1016/j.tibtech.2010.08.006

[6] K. Rostamizadeh, M. Vahedpour and S. Bozorgi, "Synthesis, Characterization and Evaluation of Computationally Designed Nanoparticles of Molecular İmprinted Polymers as Drug Delivery Systems," International Journal of Pharmaceutics, Vol. 424, No. 1-2, 2012, pp. 67-75. http://dx.doi.org/10.1016/j.ijpharm.2011.12.054

[7] Y. Q. Lv , T. W. Tan and F. Svec, "Molecular İmprinting of Proteins in Polymers Attached to the Surface of Nanomaterials for Selective Recognition of Biomacromolecules,” Biotechnology Advances, Vol. 31, No. 8, 2013, pp. 1172-1186.

[8] H. Chen, D. Yuan, Y. Li, M. Dong, Z. Chai, J. Kong and G. Fu, "Silica Nanoparticle Supported Molecularly İmprinted Polymer Layers with Varied Degrees of Crosslinking for Lysozyme Recognition,” Analytica Chimica Acta, Vol. 779, 2013, pp. 82-89. http://dx.doi.org/10.1016/j.aca.2013.03.052

[9] G. Pan, B. Zu, X. Guo, Y. Zhang, C. Li and H. Zhang, "Preparation of Molecularly İmprinted Polymer Microspheres via Reversible Addition-Fragmentation Chain Transfer Precipitation Polymerization,” Polymer, Vol. 50, No. 13, 2009, pp. 2819-2825. http://dx.doi.org/10.1016/j.polymer.2009.04.053

[10] A. Uysal, G. Demirel, E. Turan and T. Çaykara, "Dependence of Fibrinogen Recognition of Molecularly Imprinted Hydrogels on Preparation PH," Analytica Chimica Acta, Vol. 625, No. 1, 2008, pp. 110-115. http://dx.doi.org/10.1016/j.aca.2008.07.010

[11] D. Farnan, D. D. Frey and C. Horvath, "Intraparticle Mass Transfer in High-Speed Chromatography of Proteins,” Biotechnology Progress, Vol. 13, No. 4, 1997, pp. 429-439. http://dx.doi.org/10.1021/bp970044k 